\title{
CARACTERIZAÇÃO FITOSSOCIOLÓGICA DO COMPONENTE HALÓFILO-PSAMÓFILO EM UMA ÁREA DE DUNAS, SÃO LUIS, MARANHÃO, BRASIL
}

\author{
Catherine Rios Santos ${ }^{1 *}$, Ingrid Fabiana Fonseca Amorim², Eduardo Bezerra de Almeida Jr. ${ }^{1}$
}

${ }^{1}$ Departamento de Biologia, Universidade Federal do Maranhão, Cidade Universitária Dom Delgado, Av. dos Portugueses, 1966. São Luís-MA, Brasil.

${ }^{2}$ Programa de Pós-Graduação Biodiversidade e Biotecnologia da Amazônia Legal (BIONORTE), Universidade Federal do Maranhão, Cidade Universitária Dom Delgado, Av. dos Portugueses, 1966. São Luís-MA, Brasil.

*Autor correspondente: catherineriosantos@gmail.com

\begin{abstract}
RESUMO
O presente estudo teve como objetivo analisar o arranjo e distribuição da composição herbácea halófila psamófila em uma área de dunas, próximas à linha da praia, com o intuito de destacar a diversidade de espécies e assim contribuir para a conservação da vegetação de dunas. Foi realizada uma análise fitossociológica do estrato herbáceo no período de agosto de 2017 a julho de 2018, no trecho de dunas próximo à faixa da praia de São Marcos, São Luís. Foram distribuídas, ao longo da área, 50 parcelas de $1 \mathrm{~m}^{2}$ e calculados os parâmetros estruturais para as espécies e o índice de diversidade de Shannon. Como critério de inclusão para o componente herbáceo, foram consideradas as espécies que não apresentaram lignificação em toda extensão do caule. Foram identificadas 41 espécies, 34 gêneros, pertencentes a 18 famílias. As espécies que apresentaram o maior Valor de Importância foram Paspalum maritimum, Centrosema brasilianum, Crotalaria retusa, Chamaecrista hispidula e Turnera subulata. Os índices de Shannon (H') quando calculado com os valores da cobertura foi: $\mathrm{H}^{\prime} \mathrm{c}=1,58$ nats. $\mathrm{m}^{-2} \mathrm{e}$ com os valores de frequência foi $\mathrm{H}^{\prime} \mathrm{f}=3 ; 12$ nats. $\mathrm{m}^{-2}$. As espécies que mais se destacaram na área são comuns de ambientes antropizados e apresentam atributos morfológicos favoráveis aos fatores limitantes comuns em áreas de dunas.

Palavras-chave: Antropização, Parâmetros ambientais, herbácea, Restinga, Conservação.
\end{abstract}

\section{PHYSIOCHLOLOGICAL CHARACTERIZATION OF THE HALOPHIL- PSAMOPHYL COMPONENT IN A AREA OF DUNAS, SÃO LUIS, MARANHÃO STATE, BRAZIL}

\begin{abstract}
The objective of present was study had as objective to analyze the arrangement and distribution of the psamophilic herbaceous composition in an area of dunes near the beach line, with the intention of highlighting the diversity of species and thus contributing to the conservation of dune vegetation. A phytosociological analysis of the herbaceous stratum was carried out from August 2017 to July 2018, in the dune stretch near the São Marcos beach strip, municipality of São Luís. A total of $50 \mathrm{~m}^{2}$ plots were distributed and the structural parameters randomly for the species and the Shannon diversity index. As inclusion criterion for the herbaceous component, we considered the species are not lignificated along the stem extension. A total of 41 species, 34 genera and 18 families were found in the survey area. The species that presented the highest Importance Value were Paspalum maritimum, Centrosema brasilianum, Crotalaria retusa, Chamaecrista hispidula and Turnera subulata. The Shannon indices (H') when calculated with the coverage values were: $\mathrm{H}^{\prime} \mathrm{c}=1,58$ nats. $\mathrm{m}^{-2}$ and with the frequency values of $\mathrm{H}^{\prime} \mathrm{f}=3 ; 12$ nats. $\mathrm{m}^{2}$. The most prominent species in the area are common in anthropic environments and present morphological attributes favorable to common limiting factors in dune areas.

KeyWords: anthropisation, environmental parameters, herbaceous, restinga, conservation.
\end{abstract}

\section{INTRODUÇÃO}

A vegetação herbácea é caracterizada pelo seu pequeno porte e ausência de lignificação em toda sua extensão. Essas plantas são consideradas pioneiras na colonização de ambientes de dunas e restinga, possuem estratégias para garantir a

dispersão e rápido crescimento, fornecendo uma variedade de características ecológicas e taxonômicas que contribuem para a manutenção dos ambientes costeiros (Lima et al., 2015). 
A partir da distribuição do estrato herbáceo podemos avaliar as condições do ambiente. Observar como as herbáceas se desenvolvem em relação à composição lenhosa por elas influenciarem as propriedades do solo, promovendo a proteção do mesmo contra erosões com sua cobertura vegetal, além de manter as condições abióticas estáveis, como luminosidade, alterando positivamente a disponibilidade de nutrientes (Maraschin-Silva et al., 2009).

Devido às condições extremas dos ambientes costeiros, a vegetação herbácea predomina nas dunas e Restinga, cuja vegetação apresenta uma composição em mosaico com diferentes formações fisionômicas, com campos abertos e fechados, inundáveis ou não-inundáveis, no qual são encontradas predominantemente plantas herbáceas; formações de fruticetos e florestas, com presença de arbustos, lianas e árvores (Santos-Filho et al., 2010).

A vegetação herbácea das dunas se caracteriza por apresentar diferentes arranjos estruturais de acordo com as adaptações à salinidade, solo e umidade, onde a composição herbácea que se desenvolve próximo a linha da praia é denominada vegetação halófilapsamófila, estas plantas são assim denominadas devido à grande tolerância ao sal, alta mobilidade do substrato, serem tolerantes a regiões com pouca disponibilidade hídrica e pouca matéria orgânica. (Cordeiro, 2005; Boeger \& Gluzezak, 2006).

Estas formações ocorrem na maioria das restingas brasileiras, apresentando composição florística e estrutura diversa (Pereira et al., 1992). Todavia, devido às mudanças climáticas e a ações antrópicas comuns em áreas costeiras, muitas dessas áreas já foram perdidas (Menezes \& Araujo, 2005). Ações que busquem a recuperação e estabilização de dunas tornam-se de grande relevância, assim como estudos que contribuem para o conhecimento da diversidade da vegetação herbácea em ambientes costeiros em prol da conservação deste ecossistema e do seu funcionamento (Chakraborty et al., 2012). Diante desse contexto, os estudos fitossociológicos do estrato herbáceo, em áreas de dunas, são fundamentais pois contribuem para o entendimento da composição vegetal, arranjo estrutural e diversidade de uma determinada área, ajudando a compreender a distribuição das espécies nas comunidades vegetais a fim de aplicar ações adequadas de restauração (Souza et al., 2017; Oestreich-Filho, 2014).

Deste modo, o presente estudo teve como objetivo analisar o arranjo e distribuição da flora herbácea psamófila-reptante da Praia de São Marcos, com o intuito de contribuir para a conservação da vegetação de dunas e ampliar as informações sobre a flora herbácea das dunas da Ilha do Maranhão.

\section{MATERIAL E MÉTODOS}

\section{Área de estudo}

A área de estudo é caracterizada por apresentar dunas primárias paralelas à faixa da praia que são cortadas pela avenida litorânea, sendo perturbadas pela avenida de acesso principal (Cabral-freire \& Monteiro, 1994), além de extensas áreas de dunas secundárias, as quais se situam nas zonas mais interiores, com relevo íngreme e alturas elevadas (Araujo et al., 2016). $\mathrm{O}$ estudo foi desenvolvido em uma área estudada predomina vegetação herbáceas halófila-psamófila e reptantes, no período de agosto de 2017 a julho de 2018 na faixa próxima à praia, em São Marcos, no município de São Luís, Maranhão (Figura 1).

A região possui clima do tipo Aw - tropical quente e úmido (Alvares et al., 2013). A temperatura média é de $26^{\circ} \mathrm{C}$, variando entre a mínima de $24^{\circ} \mathrm{Ce}$ a máxima de $32^{\circ} \mathrm{C}$ (INMET, 2019). A Ilha apresenta dois períodos distintos: um chuvoso que se estende de janeiro a junho e outro seco, que compreende o período de julho a dezembro. A precipitação anual varia de 1.250 a $2.000 \mathrm{~mm}$ (INMET, 2019).

\section{Amostragem fitossociológica}

A amostragem fitossociológica foi realizada no período de agosto de 2017 a julho de 2018, no trecho de dunas frontais onde há o predomínio de espécies herbáceas, que são alteradas pela variação da maré, ação dos ventos e outros processos erosivos. Nesse local é possível observar um constante fluxo de pessoas, por estar localizado em um trecho turístico da praia de São Marcos.

As parcelas foram distribuídas ao longo de 10 transectos colocados perpendiculares à linha da praia com distância de $10 \mathrm{~m}$ entre si. Em cada transecto foram alocadas parcelas de $1 \mathrm{~m}^{2}$ (a esquerda ou direita de acordo com sorteio prévio) totalizando 50 parcelas para a amostragem (Munhoz \& Araújo, 2011; Lima et al., 2015). Foram consideradas plantas do estrato herbáceo as espécies que não apresentam lignificação em toda extensão do caule (Gonçalves \& Lorenzi, 2011).

A cobertura vegetal $(\mathrm{CV})$ foi obtida por meio de estimativa visual, a partir de uma parcela de $1 \mathrm{~m} \times 1 \mathrm{~m}$ subdividida em 100 quadrículos menores de $10 \times 10 \mathrm{~cm}$, correspondentes a $1 \%$ da parcela. Foram calculados ainda a Frequência Relativa (FR), Cobertura Absoluta (CA), Cobertura Relativa (CR) e o Valor de Importância (VI) das espécies de 

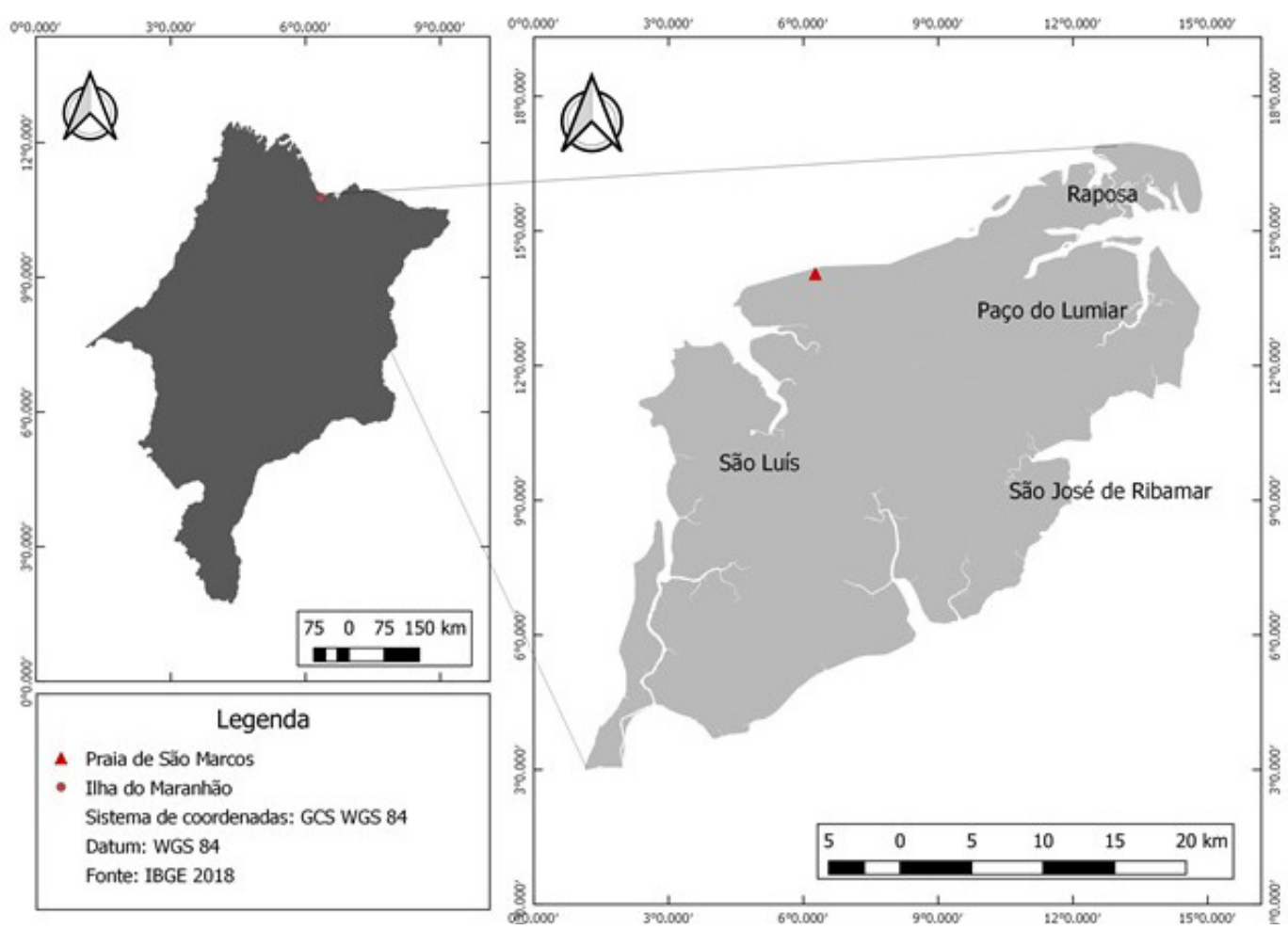

Figura 1. Mapa da Ilha do Maranhão, com a localização da Praia de São Marcos, no município de São Luís, onde foi realizada a fitossociologia de herbáceas (Fonte: Google maps e IBGE).

herbáceas encontradas (Figura 2).

O Valor de Importância (VI) das espécies foi obtido a partir da somatória da frequência e cobertura relativa (Carvalho \& Sá, 2011; Araujo et al., 2016). Os parâmetros fitossociológicos calculados para cada espécie foram realizados utilizando o pacote Microsoft ${ }^{\circledR}$ Office Excel (2010) (Mueller- Dombois \& Ellemberg, 1974; Araujo et al., 2016).

Todos os indivíduos coletados foram herborizados conforme as técnicas usuais em botânica

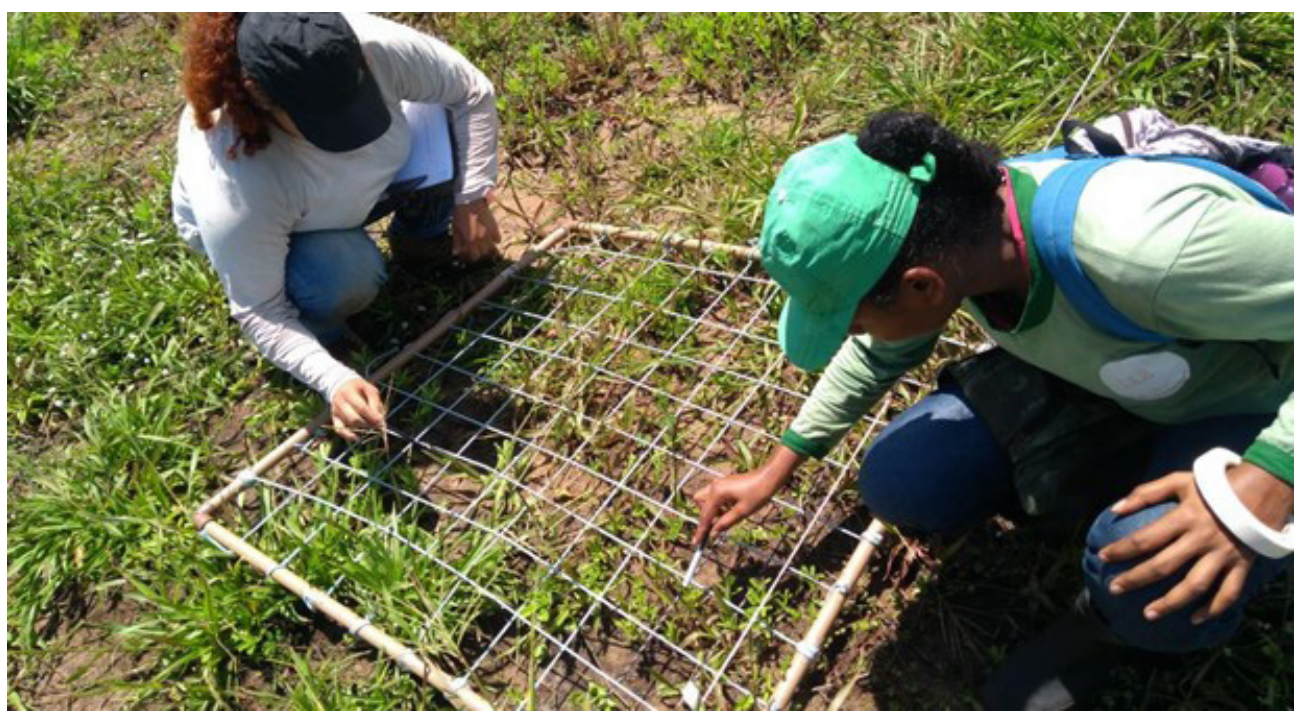

Figura 2. Imagem da parcela de $1 \times 1 \mathrm{~m}$ subdividida em 100 quadrículos menores de $10 \times 10 \mathrm{~cm}$ para a coleta dos dados fitossociológicos, praia de São Marcos, São Luís, Maranhão. 
(Peixoto \& Maia, 2013), e levados ao Laboratório de Estudos Botânicos (LEB). As amostras foram identificadas com auxílio da literatura especializada e em seguida foram depositadas no acervo do Herbário do Maranhão (MAR) do Departamento de Biologia da Universidade Federal do Maranhão (Almeida Jr., 2015). A listagem das famílias seguiu a proposta do APG IV (2016), e a grafia do nome das espécies e dos autores foi verificada por meio de consulta ao site Flora do Brasil 2020 (http://floradobrasil.jbrj.gov.br).

Para estimar a diversidade vegetal foi calculado o Índice de diversidade de Shannon-Wiener (H'). A uniformidade da distribuição dos indivíduos foi observada por meio da equabilidade de Pielou (J'). Para ambos os índices foram utilizados os dados de cobertura vegetal e frequência das espécies como medida de abundância utilizando o pacote Microsoft ${ }^{\circledR}$ Office Excel (2010) (Magurran, 1988).

\section{RESULTADOS E DISCUSSÃO}

$\mathrm{Na}$ amostragem foram identificadas 41 espécies, 34 gêneros e 18 famílias, correspondendo a 1.798 indivíduos coletados (Tabela 1). As famílias que apresentaram maior número de espécies foram Fabaceae, com 10 espécies, Euphorbiaceae com quatro espécies, seguida de Asteraceae, Convolvulaceae e Poaceae com três espécies, cada, correspondendo a $58,5 \%$ do total de espécies. A predominância dessas famílias já foi observada em outros estudos florísticos e fitossociológicos realizados em áreas de dunas costeiras do Maranhão (Amorim et al., 2016; Araújo et al., 2016; Amorim, 2017) e em outros Estados do Nordeste (Almeida Jr \& Zickel, 2009; Menezes et al., 2012; Santosfilho et al., 2015). Cabe destacar o estudo realizado por Almeida Jr \& Zickel (2009) na comunidade psamófila-reptante na Praia de Pipa, Rio Grande do Norte, onde a família Fabaceae apresentou maior número de espécies.

As espécies que apresentaram maior Valor de Importância (VI) foram Paspalum maritimum, Centrosema brasilianum, Crotalaria retusa e Chamaecrista hispidula (Tabela 1). Esses dados foram semelhantes aos resultados obtidos por Araújo et al. (2016) onde amostraram 35 espécies e Paspalum maritimum e Chamaecrista hispidula foram mais frequentes. Confirmando o sucesso reprodutivo dessas espécies às condições ambientais das dunas.

As dunas próximas à linha da costa sofrem a influência do alto grau de salinidade, erosão, escassez quanto à disponibilidade de nutrientes e ressaca das marés, criando um ambiente sob estresse que possibilita o desenvolvimento de espécies halófilaspsamófilas reptantes que atuam como estabilizadoras de dunas (Cordazzo et al., 2006). Desse modo, as dunas do presente estudo apresentaram vegetação herbácea (classificadas como halófilas-psamófilas), formadas por plantas estoloníferas, como Paspalum maritimum (Maciel et al., 2009) e reptantes, como Centrosema brasilianum e Chamaecrista hispidula (Almeida Jr \& Zickel, 2009) que se distribuíam de forma heterogênea ao longo de toda a área de estudo.

De acordo com a curva do coletor, a partir da parcela 44 o número de 41 espécies foi atingido, sendo mantido até o final (parcela 50), indicando que o tamanho amostral foi suficiente para caracterizar o arranjo estrutural das espécies do componente herbáceo halófilos-psamófilo na Praia de São Marcos (Figura 3).

A espécie Paspalum maritimum apresentou alto Valor de Importância, ocorrendo em 94\% das

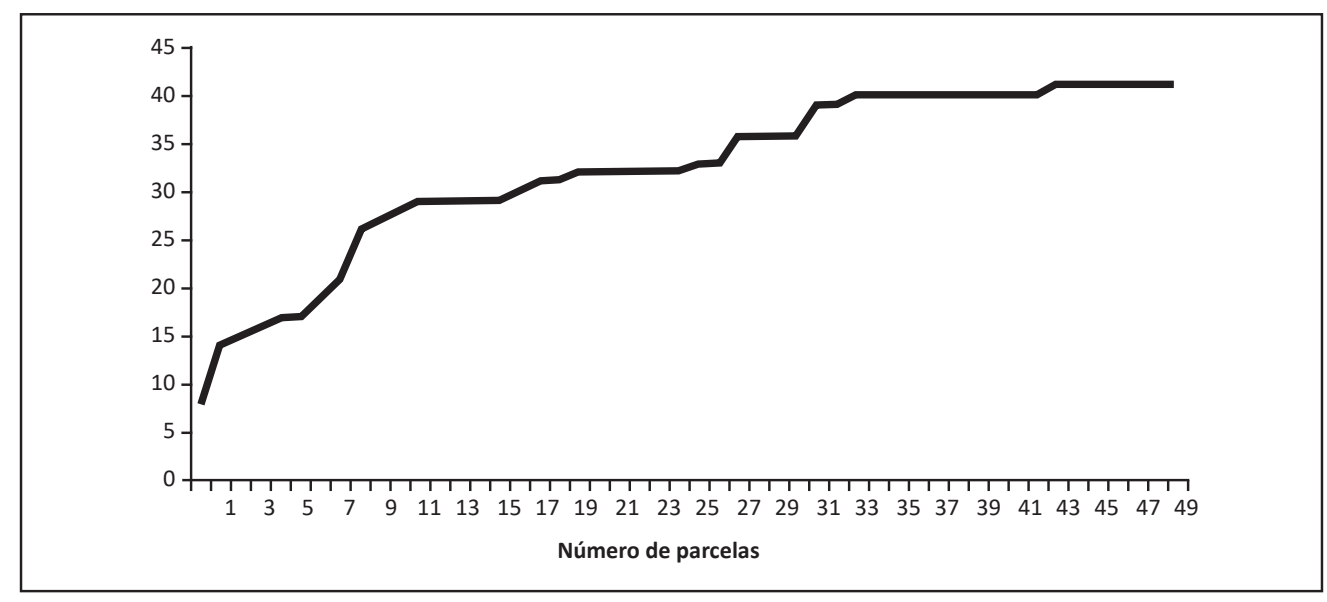

Figura 3. Curva de acumulação de espécies observadas em 50 parcelas $\left(50 \mathrm{~m}^{2}\right)$ amostradas na Praia de São Marcos, São Luís, Maranhão. 
Tabela 1. Lista das espécies herbáceas identificadas na Praia de São Marcos, São Luís, Maranhão e seus respectivos parâmetros fitossociológicos: $\mathrm{NP}=$ número de parcelas com ocorrência da espécie; $\mathrm{CA}=\mathrm{Cobertura} \mathrm{Absoluta}(\%)$; $\mathrm{CR}=$ Cobertura Relativa (\%); FA= Frequência absoluta (\%); FR= Frequência relativa (\%); VI= Valor de importância. Espécies ordenadas a partir do VI.

\begin{tabular}{|c|c|c|c|c|c|c|c|}
\hline Espécies & Famílias & NP & CA & CR & FA & FR & VI \\
\hline Paspalum maritimum Trin. & Poaceae & 47 & 2.948 & 64,48 & 1,04 & 15,90 & 80,58 \\
\hline Centrosema brasilianum (L.) Benth. & Fabaceae & 31 & 524 & 11,46 & 0,62 & 9,60 & 21,06 \\
\hline Crotalaria retusa $\mathrm{L}$. & Fabaceae & 24 & 149 & 3,26 & 0,48 & 7,43 & 10,69 \\
\hline Chamaecrista hispidula (Vahl) H.S.Irwin \& Barneby & Fabaceae & 19 & 180 & 3,94 & 0,38 & 5,88 & 9,82 \\
\hline Turnera subulata Sm. & Turneraceae & 24 & 90 & 1,97 & 0,48 & 7,43 & 9,40 \\
\hline Mimosa pudica L. & Fabaceae & 25 & 72 & 1,57 & 0,50 & 7,74 & 9,31 \\
\hline Spigelia anthelmia $\mathrm{L}$. & Loganiaceae & 19 & 44 & 0,96 & 0,38 & 5,88 & 6,84 \\
\hline Cnidoscolus urens (L.) Arthur & Euphorbiaceae & 16 & 25 & 0,55 & 0,32 & 4,95 & 5,50 \\
\hline Alternanthera brasiliana (L.) Kuntze & Amaranthaceae & 12 & 35 & 0,77 & 0,22 & 3,41 & 4,17 \\
\hline $\begin{array}{l}\text { Macroptilium atropurpureum (Sessé \& Moc. ex DC.) } \\
\text { Urb }\end{array}$ & Fabaceae & 6 & 102 & 2,23 & 0,12 & 1,86 & 4,09 \\
\hline Wedelia villosa Gardner & Asteraceae & 6 & 80 & 1,75 & 0,12 & 1,86 & 3,61 \\
\hline Alternanthera tenella Colla & Amaranthaceae & 10 & 32 & 0,70 & 0,18 & 2,79 & 3,49 \\
\hline Canavalia rosea (Sw.) DC. & Fabaceae & 7 & 47 & 1,03 & 0,14 & 2,17 & 3,20 \\
\hline Chamaecrista diphylla (L.) Greene & Fabaceae & 9 & 14 & 0,31 & 0,18 & 2,79 & 3,09 \\
\hline Ipomoea pes-caprae (L.) R. Br. & Convolvulaceae & 8 & 27 & 0,59 & 0,16 & 2,48 & 3,07 \\
\hline Pavonia cancellata (L.) Cav. & Malvaceae & 6 & 10 & 0,22 & 0,12 & 1,86 & 2,08 \\
\hline Indeterminada 1 & Indeterminada & 5 & 22 & 0,48 & 0,1 & 1,55 & 2,03 \\
\hline Zornia sp. & Fabaceae & 4 & 30 & 0,66 & 0,08 & 1,24 & 1,89 \\
\hline Richardia grandiflora (Cham. \& Schltdl.) Steud. & Rubiaceae & 4 & 23 & 0,50 & 0,08 & 1,24 & 1,74 \\
\hline Ipomoea imperati (Vahl) Griseb. & Convolvulaceae & 4 & 10 & 0,22 & 0,08 & 1,24 & 1,46 \\
\hline $\begin{array}{l}\text { Asemeia martiana (A.W. Benn.) J. F. B. Pastore \& J. } \\
\text { R. Abbott }\end{array}$ & Polygalaceae & 4 & 9 & 0,20 & 0,08 & 1,24 & 1,44 \\
\hline Sporobolus indicus (L.) R.Br & Poaceae & 2 & 21 & 0,46 & 0,04 & 0,62 & 1,08 \\
\hline Turnera pumilea L. & Turneraceae & 3 & 4 & 0,09 & 0,06 & 0,93 & 1,02 \\
\hline Astraea lobata (L.) Klotzsch & Euphorbiaceae & 3 & 3 & 0,07 & 0,06 & 0,93 & 0,99 \\
\hline Dioscorea sp. & Dioscoreaceae & 2 & 15 & 0,33 & 0,04 & 0,62 & 0,95 \\
\hline Passiflora foetida $\mathrm{L}$. & Passifloraceae & 2 & 14 & 0,31 & 0,04 & 0,62 & 0,93 \\
\hline Desmodium barbatum (L.) Benth. & Fabaceae & 2 & 8 & 0,17 & 0,04 & 0,62 & 0,79 \\
\hline Gentianaceae 1 & Gentianaceae & 2 & 7 & 0,15 & 0,04 & 0,62 & 0,77 \\
\hline Euploca poliphylla (Lehm.) J.I.M.Melo \& Semir & Boraginaceae & 2 & 4 & 0,09 & 0,04 & 0,62 & 0,71 \\
\hline Pombalia calceolaria (L.) Paula-Souza & Violaceae & 2 & 4 & 0,09 & 0,04 & 0,62 & 0,71 \\
\hline Croton hirtus L'Hér. & Euphorbiaceae & 2 & 3 & 0,07 & 0,04 & 0,62 & 0,68 \\
\hline Mollugo verticillata $\mathrm{L}$. & Molluginaceae & 1 & 5 & 0,11 & 0,02 & 0,31 & 0,42 \\
\hline Ipomoea sp. & Convolvulaceae & 1 & 3 & 0,07 & 0,02 & 0,31 & 0,38 \\
\hline Eleutheranthera ruderalis (Sw.) Sch.Bip. & Asteraceae & 1 & 2 & 0,04 & 0,02 & 0,31 & 0,35 \\
\hline Emilia fosbergii Nicolson & Asteraceae & 1 & 2 & 0,04 & 0,02 & 0,31 & 0,35 \\
\hline Bulbostylis capillaris (L.) C.B.Clarke & Cyperaceae & 1 & 1 & 0,02 & 0,02 & 0,31 & 0,33 \\
\hline Cyperaceae 1 & Cyperaceae & 1 & 1 & 0,02 & 0,02 & 0,31 & 0,33 \\
\hline Microstachys corniculata (Vahl) Griseb. & Euphorbiaceae & 1 & 1 & 0,02 & 0,02 & 0,31 & 0,33 \\
\hline Phaseolus vulgaris L. & Fabaceae & 1 & 1 & 0,02 & 0,02 & 0,31 & 0,33 \\
\hline \multicolumn{3}{|c|}{ TOTAL } & 4.572 & 100,00 & 6,46 & 100,00 & 200,00 \\
\hline
\end{tabular}


parcelas. Apresentou elevados valores de cobertura e consequentemente com a maior frequência entre as espécies amostradas, assim como registrado por Amorim et al. (2016) que destacaram P. maritimum como a espécie com maior VI da Praia Araçagi, Maranhão. A predominância dessa espécie se justifica por crescer em moitas, o que resulta numa maior fixação das dunas, provocando uma rápida cobertura do solo e dificultando a colonização de outras espécies (Santos et al., 2000). Além disso, $P$. maritimum apresenta alta cobertura à medida que se afasta da linha do mar, o que pode contribuir para maior estabilidade das dunas, juntamente com a presença de outras espécies halófilas e psamófilas.

Centrosema brasilianum foi a segunda espécie com maior VI, sendo presente em mais da metade (62\%) da área estudada. Essa espécie ajuda no estabelecimento de outras plantas por possuir simbiose com bactérias fixadoras de nitrogênio, contribuindo com características edáficas mais favoráveis ao solo (Oliveira et al., 2014). No entanto, C. brasilianum é uma planta ruderal que se desenvolve em áreas com certo grau de perturbação (Araújo et al., 2016). No estudo de Araújo et al. (2016) também foi analisado o status de conservação da vegetação da Praia de São Marcos. Os autores relataram que a área sofria diferentes perturbações antrópicas, contribuindo com a presença de espécies ruderais que são comuns de áreas antropizadas.

No estudo realizado nas dunas de Araçagi, Amorim et al. (2016) registraram a espécie Crotalaria retusa formando moitas adensadas, assim como observado no presente estudo. Cabe ressaltar que $C$. retusa apresenta dispersão explosiva e capacidade de autopolinização, não dependendo, exclusivamente, de polinizadores e dispersores de sementes naturais para se reproduzir sexuadamente. Além disso, possui alta plasticidade fenotípica, característica comum em ambientes modificados (Jacobi et al., 2005) ou perturbados e que contribui para garantir o estabelecimento e desenvolvimento dessa espécie em áreas litorâneas.

Cabe destacar, também, a ocorrência de Turnera subulata, espécie de pequeno porte e que por se desenvolver parcialmente soterradas nas dunas, apresenta alongamento caulinar rente ao solo, dando um hábito rastejante para a planta (Rocha et al., 2017). Visto que o soterramento pode atuar como fator limitante ao crescimento das plântulas ou promover o aumento das plantas adultas (Castellani \& Santos, 2006). As espécies consideradas como halófilas e psamófilas reptantes, como Canavalia rosea, por exemplo, possui estruturas que permitem o seu estabelecimento em ambientes sob estresse, pois os estolões dessa planta permitem a sua "movimentação" evitando danos provocados pelo vento e alta luminosidade (Boeger \& Gluzezak, 2006). As espécies Ipomoea imperati e Ipomoea pes-caprae desenvolvem-se na vegetação de transição halófila e psamófila reptante e conseguem se estabelecer e crescer amplamente nas áreas por causa dos rizomas que auxiliam na fixação sobre as dunas (Arruda et al., 2009).

O predomínio de halófitas e psamófilas, prostradas, verticalmente orientadas em relação ao solo, com folhas suculentas, dentre outras particularidades, permitem a colonização e sobrevivência dessas plantas em um ambiente com muita mobilidade do substrato, baixa disponibilidade de matéria orgânica, escassez de água, luminosidade direta e intensa (Boeger \& Gluzezak, 2006).

Os índices de diversidade de Shannon (H') e equabilidade de Pielou (J') apresentaram baixo valor quando a cobertura foi calculada como medida de abundância $\mathrm{H}^{\prime} \mathrm{c}=1,58$ nats. $\mathrm{m}^{-2}, \mathrm{~J}$ 'c $=0,42$. Todavia, quando a frequência foi utilizada para o cálculo dos índices obteve-se maiores valores: H'f $=3,12$ nats. $\mathrm{m}^{-2}$ e J'f $=0,84$. Apesar do alto índice de diversidade baseado na frequência, as espécies com maior VI, Paspalum maritimum, Centrosema brasilianum e Crotalaria retusa, representaram mais da metade $(60,39 \%)$ da comunidade vegetal da área. Superestimando, assim, o valor referente a diversidade, visto que essas espécies são reconhecidas como exóticas e podem inibir o desenvolvimento de espécies nativas (Amorim et al., 2016) e comuns as dunas. Desse modo, o índice de diversidade baseado na cobertura, mesmo apresentando menor valor, é o que melhor representa a realidade da vegetação de dunas, assim como relatado por Araújo et al. (2016).

Por fim, pode-se concluir que o estrato herbáceo das dunas de São Marcos possui uma alta riqueza e diversidade quando considerado o índice de frequência das espécies, diferente da cobertura vegetal, apesar dos impactos antrópicos na área $\mathrm{e}$ das peculiaridades do ambiente. As espécies que se destacaram pela frequência foram Paspalum maritimum, Centrosema brasilianum, Crotalaria retusa e Chamaecrista hispidula que se apresentaram resistentes a alta luminosidade, salinidade, pouca disponibilidade hídrica e deficiência de nutrientes no solo. Além disso, o conjunto das espécies halófilas psamófilas, de forma geral, contribuíram com a cobertura do solo por se desenvolverem em condições extremas como as dunas, favorecendo a permanência e ocorrência dessas plantas nas áreas 
costeiras.

\section{Agradecimentos}

Agradecemos à FAPEMA pelo financiamento da pesquisa e pela Bolsa de Produtividade do último autor.

\section{REFERÊNCIAS BIBLIOGRÁFICAS}

ALMEIDA JR., E.B., \& ZICKEL, C.S. 2009. Fisionomia psamófila-reptante: riqueza e composição de espécies na Praia da Pipa, Rio Grande do Norte, Brasil. Pesquisas, Botânica, 60: 289-299.

ALMEIDA JR., E.B. 2015. Herbário do Maranhão, Maranhão (MAR). Unisanta Bioscience 4(6): 129132. Edição Especial.

ALVARES, C.A., STAPE, J.L., SENTELHAS, P.C., MORAES, G., LEONARDO, J., \& SPAROVEK, G. 2013. KOPPEN. W. Climate classification map for Brazil. Meteorol, 22:711-718.

AMORIM, I.F.F. 2017. Herbáceas em áreas de dunas da ilha do Maranhão: diversidade, riqueza e conservação. Curso de Biologia, Universidade Federal do Maranhão. Dissertação (Mestrado) $67 \mathrm{f}-$

AMORIM, I.F.F., SANTOS-FILHO, F.S.\& ALMEIDA JR., E.B. 2016. Fitossociologia do estrato herbáceo de uma área de dunas em Araçagi, Maranhão. In: ALMEIDA JR., E.B. \& SANTOSFILHO, F.S. Biodiversidade do Meio Norte do Brasil: conhecimentos ecológicos e aplicações. Curitiba: 29-44.

APG IV. 2016. An update of the Angiosperm Phylogeny Group classification for the orders and families of flowering plants. Botanical Journal of the Linnean Society, 181: 1-20.

ARAUJO, A.C.M., SILVA, A.N.F. \& ALMEIDA JR., E.B. 2016. Caracterização estrutural e status de conservação do estrato herbáceo de dunas da Praia de São Marcos, Maranhão, Brasil. Acta Amazonica, 46 (3): 247-258.

ARRUDA, R.C.O., VIGLIO, N.S.F. \& BARROS, A.A.M. 2009. Anatomia foliar de halófitas e psamófilas reptantes ocorrentes na restinga de Ipitangas, Saquarema, Rio de Janeiro, Brasil. Rodriguésia, 60 (2): 333-352.

BOEGER, M.R.T. \& GLUZEZAK, R.M. 2006. Adaptações estruturais de sete espécies de plantas para as condições ambientais da área de dunas de Santa Catarina, Brasil. Iheringia, Série Botânica,
61(1-2): 73-82.

CABRAL-FREIRE, M.C. \& MONTEIRO, R. 1993. Florísticas das praias da Ilha de São Luiz, Estado do Maranhão (Brasil): Diversidade de espécies e suas ocorrências no litoral brasileiro. Acta amazônica. 23 (2-3): 125-140.

CARVALHO, D.A. \& SÁ, C.F.C. 2011. Estrutura do estrato herbáceo de uma restinga arbustiva aberta na APA de Massambaba, Rio de Janeiro, Brasil. Rodriguésia, 62 (2): 367-378.

CASTELLANI, T.T. \& SANTOS, F.A.M. 2006. Abundância, sobrevivência e crescimento de plântulas de Ipomoea pes-caprae (L.) R. Br. (Convolvulaceae) na Ilha de Santa Catarina, SC, Brasil. , 20 (4): 875-885.

CHAKRABORTY, T., MONDAL, A.K. \& PARUI, S.M. 2012. Studies on the prospects and some problems of sand dune vegetation at the fragile coastal zones of West Bengal and Orissa, in Eastern India. African Journal of Plant Science, 6: 48-56.

CORDEIRO, S.Z. 2005. Composição e distribuição da vegetação herbácea em três áreas com fisionomias distintas na Praia do Peró, Cabo Frio, RJ, Brasil1. Acta Botanica Brasilica, 19(4): 679-693.

CORDAZZO, C.V., PAIVA, J.B. \& SEELINGER, U. 2006. Plantas das dunas da costa sudoeste atlântica, USEB: Pelotas, 107 p.

GONÇALVES, E.G. \& LORENZI, H. 2011. Morfologia Vegetal: Organografia e Dicionário Ilustrado de Morfologia das Plantas Vasculares. S.1: Plantarum.

INMET. Instituto Nacional de Meteorologia. 2019. Disponível em: http://www.inmet.gov.br/portal/. Acesso em: 27 jul. 2019.

JACOBI, C.M., RAMALHO, M. \& SILVA, M. 2005. Pollination Biology of the Exotic Rattleweed Crotalaria retusa L. (Fabaceae) in NE Brazil. Biotropica, 37(3): 357-363.

LIMA, P.B., LIMA, L.F., SANTOS, B.A., TABARELLI, M. \& ZICKEL, C.S. 2015. Altered herb assemblages in fragments of the Brazilian Atlantic forest. Biological Conservation, 191: 588595.

FLORA DO BRASIL 2020 em construção. Jardim Botânico do Rio de Janeiro. Disponível em: < http:// floradobrasil.jbrj.gov.br/ > . Acesso em: 27 Jun. 2019. MACIEL, J.R., OLIVEIRA, R.C. \& ALVES, M. 
2009. Paspalum L. (Poaceae: Panicoideae: Paniceae) no estado de Pernambuco, Brasil. Acta Botanica Brasilica, 23(4): 1145-1161.

MAGURRAN, A.E. 1988. Ecological diversity and Its measurement. New Jersey: Princeton University Press. MARASCHIN-SILVA, F., SCHERER, A., \& BAPTISTA, L.R.M. 2009. Diversidade e estrutura do componente herbáceo-subarbustivo em vegetação secundária de Floresta Atlântica no sul do Brasil. Revista Brasileira de Biociências, 7 (1): 53-65.

MENEZES, C.M., ESPINHEIRA, M.J.C.L., DIAS, F.J.K. \& SILVA, V.I.S. 2012. Composição florística e fitossociologia de trechos da vegetação praial dos litorais norte e sul do Estado da Bahia. Biociências, 18(1): 35-41.

MENEZES, L.F.T. \& ARAUJO, D.S.D. 2005. Formações vegetais da Restinga da Marambaia, Rio de Janeiro. In: MENEZES, L.F.T., PEIXOTO, A.L. \& ARAUJO, D.S.D. (eds.). História Natural da Marambaia, Seropédica: EDUR, p. 67-120.

MUELLER-DOMBOIS, D. \& ELLENBERG, H. 1974. Aims and methods of vegetation ecology. Editora: John Wiley \& Sons.

MUNHOZ, C.B.R. \& ARAUJO, G.M. 2011. Métodos de amostragem do estrato herbáceo subarbustivo. In: FELFILI, J. M.; EISENLOHR, P. V., MELO, M. M. R. F., ANDRADE, L. A. \& MEIRA-NETO, J.A.A. (Orgs). Fitossociologia no Brasil: Métodos e estudos de caso. Viçosa: Editora UFV, p. 213 - 230.

OLIVEIRA, E.S.V., LIMA, J.F., SILVA, T.C. \& LANDIM, M.F. 2014. Checklist of the flora of the Restingas State of Sergipe, Northeast Brazil. Check List, 10(3): 529-549.

OESTREICH-FILHO, E. 2014. Fitossociologia, diversidade e similaridade entre fragmentos de Cerrado stricto sensu sobre neossolos quartzarênicos órticos, nos municípios de Cuiabá e Chapada dos Guimarães, Estado de Mato Grosso, Brasil. Curso de Programa de Pós-graduação em Ciências Florestais e
Ambientais, Universidade Federal de Mato Grosso, Faculdade de Engenharia Florestal, Cuiabá, $88 \mathrm{f}$. Dissertação (Mestrado).

PEIXOTO, A.L.\& MAIA, L.C. 2013. Manual de procedimentos para herbários. INCT- Herbário virtual para a Flora e os Fungos. Recife: Editora Universitária UFPE.

PEREIRA, O.J., THOMAZ, L.D. \& ARAUJO, D.S.D. 1992. Fitossociologia da vegetação de ante dunas da Restinga de Setiba/Guarapari e em Interlagos/Vila Velha, ES. Boletim do Museu de Biologia Mello Leitão, 1: 65-75.

ROCHA, L., CAMACHO, R.G.V., SALES, M.F. \& MELO, J.I.M. 2017. Flora da Região de Xingó, Alagoas e Sergipe (Brasil): Turneraceae. Rodrigésia, 68(2): 569-579.

SANTOS-FILHO, F.S., ALMEIDA JR., E.B.; SOARES, C.J.R. \& ZICKEL, C.S. 2010. Fisionomias das restingas do Delta do Parnaíba, Nordeste, Brasil. Revista Brasileira de Geografia Física, 3(1): 218-227.

SANTOS-FILHO, F.S., ALMEIDA JR., E.B., SOARES, C.J.R. \& ZICKEL, C.S. 2015. Flora and Woody Vegetation Structure in an Insular Area of Restinga in Brazil. International Journal of Ecology And Environmental Sciences, 4(3): 157-160.

SANTOS, M., ROSADO, S.C.S., OLIVEIRAFILHO, A.T. \& CARVALHO, D. 2000. Correlações entre variáveis do solo e espécies herbáceo-arbustivas de dunas em revegetação no litoral norte da Paraíba. CERNE, 6(1): 19-029.

SILVA, S.M. \& BRITEZ, R.M.A. 2005. Vegetação da planície costeira. In: MARQUES, M. C.M. \& BRITEZ, R. M. (Orgs.). História Natural e Conservação da Ilha do Mel. Curitiba, UFPR, p. 266.

SOUZA, R.F., MACHADO, S.A., GALVÃO, F. \& FIGUEIREDO FILHO, A. 2017. Fitossociologia da vegetação arbórea do Parque Nacional do Iguaçu. Ciência Florestal. 27 (3):853-869. 